
2019
Revista Vol. 22(44)
Prolegómenos julio-diciembre 2019
ISSN: 0121-182x · ISSN-e: 1909-7727
pp. 49-66

DOI: https://doi.org/10.18359/prole.3623

\title{
Los fundamentos del sistema de derechos y libertades en la Constitución de $1991^{*}$
}

\author{
Jheison Torres Ávilaa
}

\begin{abstract}
Resumen: Los derechos aparecen como columna vertebral del concepto de control del poder y de la elaboración de una teoría específica de la legitimidad estatal: el modelo liberal. En el caso colombiano, la elaboración del constitucionalismo social de 1991 trajo consigo una forma diferente de modelo estatal. Este artículo tiene por objeto examinar las características de este modelo de derechos, su configuración y definición constitucional. Para ello, se abordará, en la primera parte, el papel de la fórmula política y, con ella, de los valores del sistema constitucional de 1991. En segundo lugar, se explorará el problema de los derechos fundamentales, que establece no solo un discurso de fundamentación del sistema político-jurídico, sino que también permite el ejercicio mismo de los derechos. Por último, se definirán los derechos dentro del modelo constitucional, desde la perspectiva de la teoría jurídica contemporánea.
\end{abstract}

Palabras clave: constitución; derechos fundamentales; dignidad humana; Corte Constitucional; Estado social de derecho

Fecha de recepción: 28 de agosto de 2018 Fecha de evaluación: 28 de octubre de 2018 Fecha de aprobación: 27 de febrero de 2019

Cómo citar: Torres Ávila J. (2019). Los fundamentos del sistema de derechos y libertades en la Constitución de 1991. Revista Prolegómenos, 22(44), pp. 49-66. DOI: https://doi.org/10.18359/prole.3623

* Este artículo es producto de investigación del Grupo Constitución y Derechos humanos de la Universidad Nacional de Colombia

a Abogado y magíster de la Universidad Nacional de Colombia. Doctor en Derecho de la Universidad de Alicante; posdoctorado en curso en la Universidad de Valencia, en España. Profesor Asociado de la Universidad Nacional de Colombia.

Correo electrónico: jetorresav@unal.edu.co. 


\title{
Fundamentals of the Rights and Freedoms System in the 1991 Constitution
}

\begin{abstract}
Rights are the backbone of both the concept of power control and the development of a specific theory of state legitimacy: the liberal model. In the Colombian case, the drafting of the 1991 Constitution brought about a different form of state model. This article aims at examining the characteristics of this rights model, its configuration and constitutional definition. To this end, the role of political formula and the values of the 1991 constitutional system are addressed first. Then, the problem of fundamental rights is explored, which not only establishes a discourse to substantiate the political-legal system, but also enables the very exercise of rights. Finally, rights are defined within the constitutional model, from the perspective of contemporary legal theory.
\end{abstract}

Keywords: Constitution; fundamental rights; human dignity; Constitutional Court; social rule of law

\section{Os fundamentos do sistema de direitos e liberdades na Constituição de 1991}

Resumo: Os direitos aparecem como a espinha dorsal do conceito de controle do poder e da elaboração de uma teoria específica da legitimidade do Estado: o modelo liberal. No caso colombiano, a elaboração do constitucionalismo social de 1991 trouxe consigo uma forma diferente de modelo estatal. Este artigo tem como objetivo examinar as características desse modelo de direitos, sua configuração e definição constitucional. Para isso, na primeira parte, será abordado o papel da fórmula política e, com ela, dos valores do sistema constitucional de 1991. Em segundo lugar, será explorada a problemática dos direitos fundamentais, que estabelece não apenas um discurso de fundamentação do sistema político-jurídico, mas também permite o exercício dos direitos. Finalmente, os direitos serão definidos dentro do modelo constitucional, da perspectiva da teoria jurídica contemporânea.

Palavras-chave: constituição; direitos fundamentais; dignidade humana; Tribunal Constitucional; Estado social de direito 


\section{Introducción}

El Estado de derecho en Colombia, desde el siglo XIX, funda el orden de sus mandatos en valores y derechos que dirigen el resto del ordenamiento ${ }^{1}$. Por ello, a partir de la revisión del principio de división de poderes y de legalidad, se puede establecer que parte de estos contenidos estructuran la fórmula política ${ }^{2}$ (dignidad humana, trabajo, solidaridad, pluralismo). Así, estos principios y valores básicos cumplen funciones de limitación, tanto formal como material, a la vez que constituyen el contenido fundamental, mediante el cual se despliega la lógica del control, radicada en la división de poderes, en la vinculación legal y en la democracia ${ }^{3}$.

Sin embargo, la inclusión de tales valores y derechos, como principios de la legitimidad del Estado, implicó en su momento una versión estática de estos ${ }^{4}$, ya que se adecuaron a una visión formalista y racionalista del derecho, que impedía el cambio de aquellos en sintonía con las transformaciones del Estado y la sociedad. Es evidente que, al comienzo, dichos valores fueron acogidos como

1 Desde luego conforme a cada thelos constitucional, los derechos se modificaron y aumentaron con los tiempos. Es posible ampliar esta perspectiva con Uribe (1996).

2 La fórmula constitucional se muestra no solo como el punto de inflexión para empujar el cambio constitucional, sino también como el lugar donde se resuelve la tensión entre conservación y transformación (Canosa, 1988).

3 La constitucionalización de esos valores y su traducción en derechos evidencian un importante desarrollo, al dejar de lado la iusnaturalización a la que estaban expuestos, ocasionando su inoperatividad. Sobre el proceso de iusnaturalización y constitucionalización de los derechos ver la obra de Cruz (1989).

4 La asignación de valores por encima de otros se sitúa muy cerca del pacto entre Estado e Iglesia, que patrocina la Constitución de 1886. La aceptación de los principios católicos como la moralidad del Estado hizo que, en la práctica, se asumiera una escala e interpretación predeterminada de los valores y derechos, tal como lo sostienen Restrepo (1992) y Molina (1971). principios inmutables ${ }^{5}$, pero los hechos sociales y económicos darían cuenta de su expansión y cambio, lo cual conllevó nuevas versiones de los derechos consagrados en los primeros momentos ${ }^{6}$ de la historia institucional.

El Estado social de derecho en Colombia intenta zanjar este desafío formalista, a través de la adopción de normas que garanticen su aplicación más allá de esa interpretación restrictiva. Además, divisa en los derechos un mecanismo para construir una nueva legitimidad del sistema jurídico-político (Martínez Caballero, 1992).

Era claro, para los constituyentes de 1991, que un orden fundado en una legitimidad cuestionada, en la que el pueblo no crea en la existencia real de las libertades, debía ser reelaborado para que se recobrasen las garantías de la legitimidad, a través de la instauración de un nuevo sistema de libertades capaz de responder a los estragos de la formalización excesiva y de retornar la confianza mutua de los individuos, así como la de estos con el Estado. No se trata de entender simplemente los derechos como puros límites a la acción del Estado (De Asis Roig, 2004), sino de verlos, igualmente, como instrumentos de este que permitan crear las condiciones de realización de todos y cada uno de los mandatos de la Constitución.

Ante estas circunstancias, el presente artículo tiene por objeto acercarse a las características de este modelo de derechos, a su configuración y definición constitucional, así como a su comprensión desde la teoría constitucional y la teoría jurídica. Para ello, se revisará, en una primera parte, el papel de la fórmula política y, con ella, de los valores del sistema constitucional de 1991 para la formación e interpretación del modelo derechos, con énfasis en el concepto de la dignidad humana. En un segundo momento, se abordará el problema de

5 Sobre el iusnaturalismo en la constitución resulta pertinente la descripción de Nino (1992).

6 Es el caso del derecho de propiedad que, en 1936, sufre una importante reforma cuando se exige para su disfrute una función social, que imponía una limitación caracterizada por desmontar la visión de la propiedad como un derecho soberano sin posible morigeración (Botero Marino, 1991). 
los derechos fundamentales, que establece no solo un discurso de fundamentación del sistema político-jurídico, sino que también permite el ejercicio mismo de los derechos. Por último, se establecerán algunos puntos que definen los derechos dentro del modelo constitucional, desde la perspectiva de la teoría jurídica contemporánea.

El artículo utiliza una metodología descriptiva-prescriptiva, fundada en la elaboración dogmática del concepto de derechos fundamentales, y reconstruida a partir de la comprensión jurisprudencial de sus fuentes primarias, especialmente, durante la primera y segunda corte constitucional.

\section{El concepto de la dignidad humana como fundamento de la fórmula política}

El primer paso para recobrar la legitimidad, es decir, la aceptación e integración de las normas, en la vida pública y privada de los ciudadanos, es la necesaria reconstrucción del concepto de sujeto de derechos ${ }^{7}$, que es justamente objeto de una reflexión clave sobre la dignidad humana. De ahí que no fuera posible para la Constitución de 1991 elaborar un ordenamiento diferenciado de la tradición constitucional decimonónica, sin recobrar la centralidad de los sujetos. Esto exigió la deconstrucción del propio concepto de ley y legalidad, con el fin de buscar una dimensión de justicia material y juridicidad que trascienda la ley misma, y el replanteamiento de dicho concepto quedó, incluso,

7 En opinión de Carlos de Cabo (2001), el discurso de la rehabilitación del sujeto, en un mundo que asiste a la destrucción o deconstrucción de aquel, es simplemente la cortina de humo para afianzar ciertos sujetos y no a todos. Estos sujetos beneficiados se situarían en las multinacionales u otros macrosujetos, pero no serían los sujetos constitucionales más débiles. La rehabilitación del sujeto que se pretende no se sitúa, entonces, en este nivel, pues quiere trascender el espacio del mercado, con el fin de reconocer al individuo en su dimensión vital, fundada en la dignidad como fin y no como medio. Esta es la intención del mínimo vital: asegurar y proteger al individuo en cuanto ser humano para que alcance ciertos niveles de vida. en la elaboración de las fuentes del derecho y su relación con las jurisdicciones de paz e indígena, ejemplos que evidenciaron esta recreación.

\section{Una constitución de individuos: el ordenamiento de 1886}

La concepción de persona, en su sentido genérico, y desde la perspectiva de la Constitución de 1886, corresponde al Estado demoliberal: la representación de un individuo aislado, en apariencia enfrentado al Estado, y cuyas herramientas para defenderse son los derechos y la democracia representativa. Los valores de esa persona, si bien se fundaban en la libertad y la igualdad ante la ley, no le adjudicaban total soberanía, pues esta reposaba en una construcción conceptual basada en un sentimiento etéreo: la Nación.

Por su parte, la reforma de 1936 consagró la libertad de cultos como parte de los derechos inalienables establecidos en la Constitución, pero, como lo demostrarían los debates para la aplicación de este derecho, el Estado buscó la manera de regular la vida íntima de los ciudadanos en aras de mantener un estricto concepto del orden público y de las buenas costumbres, fundadas estas exclusivamente en los dictados del dogma católico ${ }^{8}$.

La libertad en el ordenamiento constitucional anterior a 1991, como disposición íntima y pública de un número amplio de las actuaciones de los individuos, es realmente un conjunto de competencias atribuidas de forma restrictiva. De esta manera, los derechos, bajo esta perspectiva, son dádivas graciosas, autorizaciones del Estado, pero no verdaderos derechos de la persona, independientemente de su reconocimiento estatal ${ }^{9}$. Esta

8 La Corte Suprema de Justicia, en la sentencia de constitucionalidad del 13 de marzo de 1937 (Magistrado Ponente Ricardo Hinestrosa Daza), se pronunció sobre la constitucionalidad de una ley que autorizaba la personería jurídica de las sociedades masónicas (Ley 62 de 1935). En dicha sentencia y sus salvamentos de voto, se puede reconstruir un panorama completo de la visión de la moralidad y la libertad de cultos de esa época.

9 Se reconoce, nuevamente, una influencia francesa en la construcción del orden jurídico y en particu- 
teoría del reconocimiento, como expresión de positivismo jurídico, no alcanza tampoco la impronta de garantía definida y suficientemente protectora de las libertades. La tendencia interpretativa, durante buena parte de la vigencia de la Constitución de 1886, se fundó en la comprensión de los derechos fundamentales como simples principios susceptibles de exégesis, que no reconocían de forma material las consecuencias de su aplicación. Esta comprensión de los derechos resultó estimulada por un control jurídico formal - en la mayoría de los casos- de la Constitución en manos de la Corte Suprema de Justicia.

La persona, en estas condiciones, se reducía a una entidad abstracta, que interesaba al Estado solo en la medida en que servía para garantizar el orden precapitalista de este. No había, pues, acciones y medios procesales eficaces para la protección de los derechos y la pérdida de legitimidad se convirtió en asunto cotidiano de los excluidos de este mundo constitucional. La defensa de los derechos solo era posible en los estrados judiciales, en el sistema tradicional - vía ordinaria-, que resultaba inalcanzable para los desposeídos, ya fuera por los costos que representaba o por el conocimiento que se requería para acceder a aquella. La carencia de protección efectiva condujo a la violación sistemática de los derechos, sin que los afectados poseyeran formas rápidas y eficaces de defensa ${ }^{10}$.

Con todo, debe admitirse que, durante la segunda mitad del siglo XX, se eliminaron algunas trabas a la vida democrática del país, mediante la ampliación del sufragio a las mujeres y el otorgamiento al gobierno de amplios poderes para adelantar las reformas sociales propias del keynesianismo ${ }^{11}$, que

lar de los derechos (Zagrebelsky, 2003).

10 En palabras de Ferrajoli (2001) se afirmaría que se establecieron las garantías primarias, pero se adolecía de garantías secundarias

11 Desde la reforma de 1936, se observan elementos de intervención económica y vocación estatal para el manejo de asuntos sociales. Pero serán los gobiernos del Frente Nacional los que asumirán de forma más clara los mecanismos de la economía keynesiana. Se destaca, en el aspecto constitucional, la reforma de 1968 del gobierno de Carlos Lleras Restrepo, como consolidación legal de esta propiciaron un incremento en la mejora de las condiciones de vida de las clases medias y trabajadoras. Paradójicamente, estos cambios se realizaron bajo el régimen político del Frente Nacional, que terminó por sepultar la democracia y la posibilidad real de participación del pueblo. A pesar de estos cambios, nunca se cuestionó la lectura tradicional de sujeto de derechos, que resultaba relevante para el desarrollo jurídico-político de la categoría de los derechos fundamentales. Por ello, estos pasos terminaron convirtiéndose en factores de frustración para la inmensa mayoría de la población e incluso siempre estuvieron presentes en los intentos de reforma constitucional de las décadas de los años setenta y ochenta.

Así las cosas, la concepción de persona en el anterior ordenamiento se caracterizó porque, en primer lugar, el individuo estaba enfrentado al Estado; aunque, en segundo lugar, dicho enfrentamiento no se producía en términos abiertos e igualitarios, pues en últimas se terminaba por favorecer al poder estatal; en tercer lugar, se rescataba exclusivamente como esencia del individuo el sujeto económico; en cuarto, se negaban las distintas opciones y posibilidades de un desarrollo libre y autónomo del sujeto; en quinto lugar, el paternalismo y la jerarquización social precedían al concepto de individuo, y, por último, los deberes y obligaciones del individuo se disolvían frente a las lealtades autoritarias: tradición y poder político ${ }^{12}$.

forma económica que se combina con las recomendaciones de la Cepal. Ahora bien, en el aspecto político, la ampliación democrática se queda en el supuesto del plebiscito de 1958, pues es en este mismo momento cuando se instaura el régimen antidemocrático del Frente Nacional, que repartía el poder entre los partidos tradicionales. Uribe Vargas (1996) y Pécaut (1989) se han concentrado en el contenido de la reforma de 1968.

12 Con respecto a la tradición, una semblanza de los albores de este debate de persona se ha presentado, de manera reiterada, en el desarrollo de la Constitución de 1991, y uno de los casos en los que esta posición, al parecer cada vez más minoritaria, triunfó frente a las expectativas de una cláusula general de libertad, que se desprende del concepto de persona, es el referente al tema de aborto. En la sentencia C-133 de 1994, se prefiere una visión 
Sin un sujeto a partir del cual se pueda recomponer el orden institucional, era imposible el progreso y la integración de la sociedad ${ }^{13}$. Esta es la lección que dejan las distintas experiencias de 105 años de vigencia de la Carta de 1886. En idéntico sentido, la falta de conexión entre las instituciones políticas y la sociedad producen una fragmentación de esta, que mantiene al individuo aislado y lo imposibilita para construirse como un sujeto con ciudadanía social (Bottomore y Marshall, 1998). Por otra parte, los canales de cambio político fueron obstruidos durante décadas por la cooptación y la corrupción, lo cual motivó, posiblemente, a diferentes fuerzas sociales a enfrentarse con el Estado en un conflicto armado que todavía se prolonga. No cabe duda de que la carencia de medios eficaces para garantizar la legitimidad de los valores constitucionales en condiciones de justicia social fue, en gran medida, el caldo de cultivo de los trastornos que ha sufrido el Estado colombiano. Esta situación impulsó la recreación de un nuevo sujeto conforme a las demandas populares y la necesidad de relegitimación del sistema político ${ }^{14}$.

\section{La dignidad humana: la persona como epicentro de la Constitución de 1991}

Los derechos liberales son insuficientes para construir a partir de ellos la legitimidad del Estado. Ha

restrictiva de la libertad y de los derechos de la persona, fundada en la moralidad pública. Esta postura cambió en la sentencia que examinó la constitucionalidad de la eutanasia pasiva.

13 Desde luego, el proyecto político de la Constitución se funda en la virtualidad del derecho y no en la movilización política. Por ello, la rehabilitación del sujeto es indispensable. Esto, sin duda, funda la crítica, en el contexto colombiano, de que los derechos constitucionales son un argumento en contra de la movilización social.

14 No se debe olvidar que la rehabilitación del sujeto constitucional no se identifica con la de individuo. Es decir, en el nuevo constitucionalismo se reconocen diversos sujetos sociales que pueden actuar como entes autónomos para reivindicar sus derechos. Esto para intentar la superación del sujeto creado por el paradigma liberal (Nino, 1989). sido necesario, por lo tanto, proponer un nuevo fundamento que los irradie, que recupere su dinamismo y que opere como garantía esencial para la vida de la persona. Este es el sentido del artículo 1 de la Constitución de 1991: fundar un nuevo orden político-social, cuya base sea, precisamente, el ser humano. En este sentido, la sentencia 401 de 1992 indicó que "la dignidad, como principio fundante del Estado, tiene valor absoluto no susceptible de ser limitado ni relativizado bajo ninguna circunstancia, lo que a menudo sí acaece con los derechos que deben necesariamente coexistir con otros y admiten variadas restricciones" (Corte Constitucional, 1992).

La jurisprudencia colombiana ha interpretado la dignidad humana ${ }^{15}$ como principio y sus manifestaciones como derecho fundante del orden constitucional. Esto quiere decir que los derechos, como expresión directa de la dignidad humana, se convierten en garantía y base de la legitimidad. Las aplicaciones de este principio son innumerables en la jurisprudencia, ya que atraviesan todo el espectro jurídico e intervienen, por ejemplo, tanto en tratamientos de los enfermos de sida, en la eutanasia y en el libre desarrollo de la personalidad como en la generación de obligaciones de individuos o entidades frente a otros ${ }^{16}$. En la jurisprudencia anteriormente citada se esboza la estructura sobre uno de los temas más destacados de la interpretación constitucional contemporánea: el mínimo vital. La dignidad humana es el sustento con el cual se construye un derecho complejo como este; si no fuera así, esta se encontraría en serio peligro al no poder concretarse en las diversas manifestaciones que se derivan de su aplicación.

Este punto de vista del ser humano como algo revestido de dignidad trajo al ordenamiento nuevas sensibilidades de las que carecía lo jurídico.

15 La dignidad humana como principio ha sido ampliamente desarrollada. Es posible ampliar esta descripción con Oehling de los Reyes (2010), Benda (1996), Von Munch (1982), Serna Bermúdez (1995) y Nino (1989).

16 Ver, entre otras, las sentencias T-402 de 1992, T-221 de 1995, SU-111 de 1997, C-139 de 1996, C-251 de 1997, T-1218 de 2005, C-804 de 2006, T-381 de 2014. 
La aceptación de la dignidad humana conduce al estudio de los distintos grupos poblacionales como titulares de dicha dignidad. En el marco de la pluralidad recogida en la fórmula política y del ser humano como epicentro de la Constitución, los niños (artículo 44), los ancianos (artículo 46) $y$, en general, los grupos vulnerables mayormente expuestos a sufrir menoscabo a su dignidad son los principales sujetos amparados por la protección constitucional.

Estas consideraciones, a propósito del principio de la dignidad humana, tienen consecuencias inmediatas sobre la interpretación y aplicación de los derechos. Sin consecuencias jurídicas, la dignidad humana, como valor constitucional, carecería de un marco real de aplicación. Así, la Corte Constitucional colombiana comparte con los ordenamientos alemán y español ${ }^{17}$ los siguientes efectos:

1. Principio de tutela del 'contenido esencial' de los derechos. Con este postulado se pretende que la dignidad humana se proteja como núcleo fundamental de todos los derechos, de acuerdo con una lectura sistemática y a partir de su fundamentación axiológica.

2. Principio de aplicación inmediata. Sobre este punto en particular, la Corte Constitucional ${ }^{18}$ ha dejado claro que todos los derechos son de aplicación inmediata. Entendiendo por ello lo dispuesto en el artículo 1.3 de la Ley Fundamental alemana, lo mismo que en el 53.1 de la Constitución española ${ }^{19}$, es decir, la vinculación de los derechos como

17 Las diferencias entre los tribunales europeos y el nacional residen en la intensidad con que esos postulados son aplicados y en los derechos que cubren. En temas de derechos que abarcan acciones positivas del Estado, estos axiomas tienen aplicación restrictiva en los primeros y algunas veces en el segundo. También se harán patentes diferencias en las consecuencias según los derechos, puesto que cada ordenamiento establece las jerarquías de derechos de manera distinta.

18 No solo los derechos, la Constitución en general goza de ese carácter como norma (C-155, 1999).

19 El artículo 1, No 3., de la Constitución alemana dice: "los derechos fundamentales relacionados a continuación vinculan a los poderes legislativo, ejecutivo y judicial a título de derecho inmediatamente pautas obligatorias para los poderes públicos y como parte integral del thelos constitucional. Sin embargo, la aplicación inmediata tiene varios aspectos que es necesario tener en cuenta. Por una parte, saber si el principio de aplicación inmediata implica la posibilidad de ejercer la acción de tutela para toda clase de derechos. Por otra, en el caso particular de los derechos sociales, saber si, además de la tutela, dicha aplicación inmediata se puede leer como eficacia inmediata, es decir, como un mandato que compromete, sin desarrollo legal y sin dilaciones, a las autoridades correspondientes a iniciar acciones para la protección y desarrollo del derecho. Todos los derechos, en aplicación del reconocimiento de la dignidad humana como valor fundante, no responden a expresiones programáticas y gozan del mismo valor que otras normas, en el sentido del artículo 4 de la Constitución Política, es decir, el del principio de eficacia normativa directa.

3. Principio de la interpretación más favorable. En observancia del artículo 4, todas las normas del ordenamiento deben ser interpretadas de manera que se busque no solo la constitucionalidad de estas, sino que deberá tenerse como objetivo el desarrollo y la efectividad de los derechos. Este tipo de interpretación es la piedra angular que permite dotar al sistema constitucional de auténtico dinamismo. No basta, por lo tanto, con una observancia material y formal de los derechos como objetos "dados" de antemano por la Constitución, ya que estos se encuentran siempre en movimiento $^{20}$, conforme a las necesidades de los seres humanos y de la sociedad, obligando, de acuerdo con las diferentes circunstancias, a efectuar los

aplicable.”; el artículo 53 de la Constitución española establece: "1. Los derechos y libertades reconocidos en el Capítulo segundo del presente título vinculan a todos los poderes públicos. Sólo por ley, que en todo caso deberá respetar su contenido esencial, podrá regularse el ejercicio de tales derechos y libertades, que se tutelarán de acuerdo con lo previsto en el artículo 161.1.a)”.

20 Desde luego, esto implica que la lectura propuesta se realiza desde una perspectiva externa al modelo iusnaturalista de los derechos o conforme a la teoría interna de los derechos (Borowski, 2003). 
ajustes hermenéuticos necesarios. Por otra parte, la Carta fundamental contiene, igualmente, derechos, cuya realización es de carácter progresiva; así, las normas que tengan ese carácter deberán apuntar a que día a día se consolide su disfrute efectivo.

4. Principio de la eficacia frente a terceros o frente a particulares. Como parte del concepto de persona en la Constitución de 1991, la eficacia de los derechos no se entiende únicamente de forma vertical, es decir, del Estado y sus órganos hacia el ciudadano, sino que el principio de la dignidad humana produce una ruptura con la visión liberal, de acuerdo con la cual los negocios y asuntos de carácter privado, por hacer parte de la autonomía de la voluntad, no permiten la injerencia del Estado. La Constitución, por el contrario, autoriza la injerencia de este en la vida de los individuos, como parte del orden de valores que el poder público esté llamado a propiciar. De este presupuesto se desprende la posibilidad inequívoca de exigir, por vía de tutela, el respeto de los derechos fundamentales frente a los excesos en los que puedan incurrir los particulares que efectivamente lesionan dichos derechos ${ }^{21}$.

De otra parte, la aproximación al concepto de persona corresponde precisamente a la intención del constituyente de abandonar la interpretación, según la cual solo quienes gozan de derechos políticos pueden ser los destinatarios de la tutela del Estado ${ }^{22}$. Es evidente que restricciones de este tipo generan un sinnúmero de desigualdades, que terminan por menoscabar la legitimidad que se atribuye al Estado, gracias a la protección que

21 La Drittwirkung del derecho alemán, en el ordenamiento nacional, no tuvo mayores problemas para su aplicación, ya que las normas que regularon el asunto, especialmente el decreto que reglamentó la tutela, de forma expresa dejaron abierta la posibilidad de su aplicación a los actos lesivos de los particulares con respecto a los derechos fundamentales de otra persona (Estrada, 2000).

22 Esta intención se refleja en la forma de operar de la acción de tutela, en la que incluso los niños pueden presentar acciones a los jueces para que ellos los protejan, evitando filtros que terminen por vulnerar la dignidad que se intenta defender. otorga a los derechos fundamentales. Los derechos tienen sentido si son reconocidos y aplicados a todos y cada uno de los individuos que habitan en el país, debido al carácter universal de la dignidad humana. Esta se constituye en la base para la configuración de un orden institucional justo e igualitario desde el punto de vista conceptual, lo cual no resulta posible desde el concepto clásico de ciudadanía ${ }^{23}$.

El principio de la dignidad humana, además de ser accionable por cualquier persona, debe ser respetado por todos los poderes públicos y servir de pauta general en todas sus actuaciones dado su carácter obligatorio (artículo 4). En este sentido, se ha pronunciado la Corte Constitucional, en la sentencia T-521:

El reconocimiento superior de la dignidad como principio fundante de nuestro ordenamiento constitucional "exige un trato especial para el individuo, de tal forma que la persona se constituye en un fin para el Estado que vincula y legitima a todos los poderes públicos, en especial al juez, que en su función hermenéutica debe convertir este principio en un parámetro interpretativo de todas las normas del ordenamiento jurídico". De lo expuesto fluye que cuando el Estado, independientemente de cualquier consideración histórica, cultural, política o social, establece normas sustanciales o procedimentales dirigidas a regular las libertades, derechos o deberes del individuo, sin tener presente el valor superior de la dignidad humana, serán regulaciones lógica y sociológicamente inadecuadas a la índole de la condición personal del ser humano y, por contera, contrarias a la Constitución, en la medida en que se afectarían igualmente los derechos fundamentales, dado que éstos

23 El punto no es pacífico. La defensa de la ciudadanía como condición de igualdad se expresa en la teoría de T.H. Marshall, pues la ciudadanía social es la base fundamental para el logro de la igualdad. Aquí, al referirnos a la ciudadanía, se concibe en su acepción formal que se aprecia en el constitucionalismo del siglo XIX, al considerar ciudadanos a aquellos que tienen cierto nivel de renta y de educación -sistema censitario-. Sobre la dignidad humana como condición de igualdad es posible consultar a Benda (1996). 
constituyen condiciones mínimas para la "vida digna" del ser humano; en efecto, cuando se alude a los derechos fundamentales se hace referencia a aquéllos valores que son anejos a la dignidad humana. (1998)

En resumen, las características de la persona previstas en el ordenamiento jurídico colombiano, conforme a la Constitución y la jurisprudencia constitucional serán: calificación de la persona como ser humano, es decir, fuera de otras consideraciones (por ejemplo, la calidad de la ciudadanía); reconocimiento de su diversidad (artículos $7,18,19,20)$; reconocimiento de la necesidad de disfrutar de condiciones óptimas tanto materiales (bienes y servicios; artículos 13, 51) como físicas (integridad; artículos 11, 12, 49, 52); plena autonomía, aunque sometida a los límites que imponen los derechos ajenos y el principio de solidaridad (artículo 16, artículo 95; deberes y obligaciones); abandono del concepto del individuo autárquico (artículo 88; acciones de populares y de grupo, y artículo 79). Se espera, además, que la persona participe de las funciones del Estado a través de los mecanismos de participación (artículo 103) y que contribuya a la realización de sus objetivos sociales, siempre desde la perspectiva del disfrute de su libertad efectiva. Los individuos ya no se enfrentan al Estado; lo convierten en herramienta para la búsqueda de un orden más justo, por medio del freno de la arbitrariedad y la desigualdad (artículo 2). Se trata, en definitiva, de un individuo que se apoya en el Estado para desarrollar todas sus potencialidades como ser humano.

\section{Los derechos fundamentales como ejes del sistema de derechos}

Los derechos hacen parte esencial de la concepción del Estado de derecho. En ellos residen los valores esenciales de la revolución republicana. La propiedad, la igualdad y la libertad corresponden a los ideales centrales de los dirigentes revolucionarios responsables de elaborar las primeras constituciones entre el siglo XVIII y el XIX ${ }^{24}$. Por ello, siguiendo la ruta inicialmente trazada, una vez que se ha establecido la dignidad humana como valor fundamental del sistema político-jurídico, se hace necesaria una revisión del sistema de derechos propiamente dicho, como parte de la fórmula política del Estado colombiano ${ }^{25}$.

El ordenamiento constitucional del país dispone, en El título II, el sistema de derechos y lleva como título: "De los derechos, las garantías y los deberes". Este, a la vez, se divide en cinco capítulos, en los que se hace mención, en los tres primeros, a los derechos; en los restantes se tratan las garantías, gracias a las cuales pueden ser exigibles, así como los deberes que se incorporan como parte de todo el sistema de derechos. El capítulo primero se denomina "De los derechos fundamentales"; el segundo, "De los derechos sociales, económicos y culturales"; el tercero, "De los derechos colectivos y del medio ambiente"; el cuarto, "De la protección y aplicación de los derechos", y el quinto: "De los deberes y obligaciones".

Como se observa, se intenta hacer una clasificación entre derechos de primera, segunda y tercera generación. Pero dicha clasificación es infortunada, ya que se advierte con facilidad que, aunque el criterio histórico adoptado pudiese ser el mejor, dicha división no se respeta, puesto que los derechos del capítulo primero no son en puridad de verdad todos derechos de primera generación. Son, en realidad, derechos que expresan libertades y límites frente al poder público, con lo cual se entiende su razón, pero no su claridad desde una perspectiva

24 “Allí donde no hay Constitución (y habrá que ver si cualquier Constitución vale) no habrá derechos fundamentales. Habrá otras cosas, con seguridad más importantes, derechos humanos, dignidad de la persona; habrá cosas parecidas, acaso igual de importantes, libertades públicas francesas, derechos públicos subjetivos alemanes; habrá, en fin, cosas distintas, como fueros o privilegios. Pero no habrá derechos fundamentales” (Cruz Villalon, 1989, p. 41).

25 En este apartado se insiste en una exposición del sistema de derechos de la Constitución colombiana, y se evitan consideraciones sobre teoría general de los derechos. 
exclusivamente histórica. Además, dentro de las libertades del mismo capítulo, primero se consagran derechos como el trabajo, el de asociación o a la paz, que no corresponden al primer momento de los derechos (Peces Barba, 1998; 1999).

Pero el mayor problema no es el no cumplimiento de la rigidez que impondría la clasificación histórica, sino el título que lleva este: "De los derechos fundamentales"; el título segundo, y en consonancia con la clasificación histórica referida su encabezamiento: "De los derechos sociales, económicos y culturales", y el tercero, "De los derechos colectivos y del medio ambiente"; adicionalmente, existen otros derechos en la Constitución que no se incluyen en ninguno de los títulos aludidos, como es el caso del derecho a la libre competencia y a la libertad económica del artículo 333. Esto parece mostrar que solo los derechos mencionados en el título primero son derechos fundamentales, aunque quedaría por resolver que sucede con los demás derechos dispersos por todo el texto constitucional, y que están fuera de los capítulos citados. Aquello merece una breve revisión para poder comprender mejor el sistema de derechos de la Constitución de 1991.

Aún suponiendo que esta clasificación de tipo historicista sea la mejor para expresar la carta de derechos del Estado social colombiano, el título primero advierte que son estos, los contenidos en dicho título, los "únicos y verdaderos" derechos fundamentales, lo cual siembra la duda de si los demás no son fundamentales. Una interpretación de tipo formalista, y que, sobre todo, desatienda los mandatos del Estado social, seguramente zanjaría el debate acerca de la interpretación en torno a la clasificación de los derechos, asumiendo simplemente lo que establece el título aludido. No obstante, el problema es mucho más complejo, porque si se repara en los derechos expresados en los dos títulos restantes y, en especial, si se revisan diversos derechos del Título II, como la huelga o los derechos de los niños, se ve con facilidad que algunos de ellos hacen parte, sin duda, del núcleo duro de los que se consideran derechos fundamentales. Incluso, no solo para el constitucionalismo del Estado social sino -y desde una perspectiva amplia- desde el punto de mira del ordenamiento anterior, que ya incorporaba algunos de esos derechos $^{26}$. Así las cosas, por lo menos algunos derechos de los títulos restantes constituyen verdaderos derechos fundamentales, lo cual pone de manifiesto la imposibilidad de seguir un criterio formal o literal en la clasificación de aquellos. De esta manera, tendría que ser la jurisprudencia constitucional y la doctrina las que clasificaran los derechos, de acuerdo con lo que el constituyente quiso expresar.

La problemática sobre la disposición de los derechos trae enormes consecuencias, en especial, a la hora de accionar, ya sea en tutela, control de constitucionalidad o mediante las acciones populares. También se observan notables consecuencias al definir el alcance y regulación de los derechos, pues cuando se trata de los fundamentales, estos no se pueden cumplir más que por medio de leyes estatutarias. Tampoco es posible la suspensión de tales derechos bajo el régimen de los "estados de excepción", como también debe ser tenida en cuenta esta categoría para la determinación de ciertas violaciones al régimen disciplinario de los funcionarios públicos, entre otros.

\section{La determinación de los derechos fundamentales en la Constitución de 1991}

Ante las dificultades que se desprenden de su inapropiada titulación, y la carencia de una lista taxativa de los derechos, la Corte Constitucional ha asumido diversas formas de determinar cuáles son

26 Cabe aclarar que, para la Constitución de 1886, los derechos fundamentales como categoría son inexistentes; la característica más destacada de los derechos en dicha Constitución es su generalidad y el hecho de que, además, carecen de protección reforzada. Para el constitucionalismo del 86, los derechos fundamentales son de una vaguedad y uso diferente al que se refiere como derechos con garantías reforzadas. Para este constitucionalismo, los derechos fundamentales son aquellos que son esenciales para la vida del Estado y la sociedad, pero que no comportan dicha protección extraordinaria. Los derechos de huelga y sindicación fueron incluidos en dicha Carta por reformas de su texto original, y en ese sentido amplio y difuso eran derechos fundamentales. 
derechos fundamentales, adjudicando diferentes efectos institucionales" ${ }^{27}$. Así las cosas, "no todos los derechos que estamos dispuestos a calificar de fundamentales lo son para los mismos efectos y en todos los diferentes sentidos de fundamentalidad. En el sentir de la Corte Constitucional, un derecho puede ser catalogable como fundamental, en el sentido del derecho cuya vulneración en un caso concreto puede ser impedida o corregida por el remedio de la acción de tutela; pero no puede serlo en el sentido que su regulación exige una ley estatutaria." (Chinchilla, p. 74) ${ }^{28}$

La primera forma de identificación de los derechos la ofreció la propia Carta, en virtud de lo dispuesto en el artículo 85, al señalar explícitamente cuáles derechos mencionados en el texto constitucional gozan de aplicación directa. Los derechos enumerados en la citada norma hacen referencia en su mayoría a los derechos de primera generación. Con todo, la Corte Constitucional no se conformó con dicha interpretación restrictiva, y adoptó diferentes sistemas de reconocimiento de los derechos fundamentales, siempre en una relación inescindible con la acción de tutela. La Corte desmontó el argumento formal de la siguiente manera:

1. El argumento originalista como fuente de interpretación basada en la literalidad. Al realizar la investigación sobre las actas de la constituyente, quedó claro para la Corte Constitucional que los diferentes títulos y capítulos en los que se divide el texto de la Constitución no fueron el resultado ni de consensos ni menos de votaciones en el interior de la Asamblea Constituyente, sino de una comisión codificadora designada por la propia asamblea, pero cuyo trabajo en cuanto a la organización del texto constitucional nunca recibió el aval de parte del cuerpo constituyente. Por otra parte, diversos delegatarios se manifestaron

27 Contrario a lo que afirma con imprecisión Aguilar de Luque (2001), al referirse al reconocimiento de los derechos fundamentales en Colombia con criterios iusnaturalistas.

28 Chinchilla (1999) presenta como ejemplo el caso del derecho a la seguridad social y el derecho de propiedad, que no requieren ese trato especial por vía legal. expresamente a favor de que los derechos fundamentales quedaran al arbitrio o bien del juez o del legislador ${ }^{29}$.

2. La interpretación sistemática. Además de los derechos denominados como fundamentales, otros derechos - determinados esta vez por consenso- se elevan a esa máxima categoría. Tal es el caso de los derechos de los niños, que recogen derechos individuales y sociales.

3. La argumentación axiológica. El constituyente no dio indicio alguno para que, desde el punto de vista axiológico, unos derechos tengan mayor valor que otros en función de su disposición en el texto de la Constitución. De tal suerte que será la Corte Constitucional la que definirá cuáles derechos poseen un valor especial para la vida del Estado y de los individuos.

Queda claro, por lo tanto, por qué no se acoge la mirada restrictiva de los derechos basada en la titulación o incluso en un espurio criterio histórico. Ahora compete señalar cuáles son esos derechos que merecen ser llamados fundamentales y en qué sentido lo son. Los criterios para seguir son (Chinchilla, 1999):

1. Criterio material. Este criterio se desprende del efecto que produce la fórmula política del Estado social de derecho en Colombia. En este sentido, se identifican dos posibles caminos relacionados con dicha fórmula: la dignidad humana y la conexión con otros valores o principios como ejes del sistema constitucional. De esta manera, según la sentencia T-571, "el carácter de fundamental de un derecho no depende de su ubicación dentro de un texto constitucional, sino que son fundamentales aquellos derechos inherentes a la persona humana" (Corte Constitucional, 1992).

Además, según la sentencia T-810, "es la realidad de cada caso concreto, las circunstancias únicas y particulares que lo caracterizan, las que permiten definir si se encuentra verdaderamente vulnerado un derecho fundamental, si ello afecta la dignidad de la parte actora y si esta última está en

29 Gaceta Constitucional, Núm. 24 pág. 7. La Corte Constitucional, por sentencia C-134 de 1994, negó la competencia al legislador. 
situación de indefensión frente al presunto agresor. En otras palabras, en el juicio de tutela los requisitos procesales sólo pueden ser integralmente verificados previo estudio de la materialidad del caso concreto y no a priori o en abstracto. Justamente ese es uno de los distintivos esenciales que diferencian el proceso constitucional de otros procesos reglados hasta el detalle por el derecho legislado" (Corte Constitucional, 1998).

2. Criterio formal. La literalidad del artículo 44 (derechos de los niños), la expresión del título I y del artículo 85 (aplicación inmediata), si bien no conforman un criterio infalible sobre la fundamentalidad, sí constituyen un indicio de cuál puede ser. De ahí que la mención de estos derechos deba ser atendida. La desarticulación del criterio formal, entonces, solo corresponde a su expresión como numerus clausus, pero no como indicador válido exclusivo.

3. La aplicabilidad inmediata y el núcleo esencial. La Corte Constitucional asume estas características de los derechos como mecanismos para determinar si estamos frente a un derecho fundamental. Respecto de la eficacia directa, la Corte, al interpretar el artículo 85, niega que sea una lista taxativa pudiendo ser, además de los derechos enumerados en el artículo, otros los que puedan gozar de tal reconocimiento.

El núcleo esencial del derecho, definido por la Corte, en la sentencia T-426, es "el ámbito necesario e irreductible de conducta que el derecho protege con independencia de las modalidades que asuma o de las formas en que él se manifieste" (1992). Será este un rasgo para definir un derecho fundamental, ya que posee dicho núcleo que no está al arbitrio de las mayorías parlamentarias, y será el que recibe la protección reforzada de la tutela.

4. Los tratados internacionales de derechos. Otro indicador para saber si se está ante un derecho fundamental es el que se deriva del artículo 93, que confiere fuerza normativa interna a los tratados internacionales sobre derechos humanos. Si dichos tratados prohíben su limitación en Estados de excepción, hay una vía de interpretación que permite reconocer la fundamentalidad de un derecho.
5. El referendo derogatorio del artículo 377. La Carta, en su artículo 377, establece que los derechos del título I y sus garantías, los procedimientos de participación popular o las normas sobre organización y funcionamiento del Congreso, deben ser sometidos a referendo en los eventos en que tales disposiciones sufran modificaciones de parte del constituyente derivado. De esta manera, los derechos fundamentales del título primero sirven de criterio orientador para considerar estos como fundamentales.

6. La conexidad. Opera cuando se trata de tutelar un derecho en un caso concreto, que se encuentre íntimamente relacionado con otro derecho al que sí se le reconoce dicha fundamentalidad. En la evaluación que realice el juez, se deberá establecer que sin la protección del derecho carente de fundamentalidad, el que sí la tiene se verá menoscabado.

No cabe duda de que el criterio de conexidad fue durante más de una década la herramienta heurística principal para la operación de la tutela con respecto a los derechos prestacionales. Ante la negativa de su protección, o por virtud de su difícil fundamentación desde el "nudo", argumento axiológico en el caso concreto, pueden dichos derechos ser efectivamente garantizados cuando la situación límite presenta tal gravedad que afecta bienes que inequívocamente son tutelables.

La conexidad se funda en el nuevo rol que ejerce el juez, ya que este no se debe limitar a constatar un hecho para dar paso a las consecuencias normativas. En este proceso de aplicación del derecho, la evaluación de la fundamentalidad de los derechos requiere de un juez que evalúe las condiciones que rodean el caso, sus consecuencias y sus posibilidades fácticas y jurídicas. En palabras de la Corte se debe utilizar el subcriterio denominado "criterio de realidad social" (Chinchilla, 1999, p. 102), en el que los sujetos de la acción deben evaluarse según su posición de afectado, valorando los peligros a que se someten en caso de no tutelarse el derecho.

De acuerdo con lo anterior, no debe resultar extraño el creciente interés de la doctrina colombiana por la literatura referida a los derechos y al 
papel de los jueces como garantes de ellos, pues los canales de aplicación de la Constitución son de enorme novedad y trascendencia. Esta circunstancia requerirá de un esfuerzo importante de la Corte Constitucional y del legislador para depurar procedimientos, otorgándoles seguridad y firmeza.

El criterio de conexidad ha sido utilizado, entre otros, en derechos: derecho a la pensión (T-177 de 1998); pensión por invalidez (T-553 de 1998); pensión por vejez (T-163 de 1996); derecho a la propiedad (T-554 de 1998), derecho a la recreación (T-410 de 1999); derecho a la salud (T-312 de 1996, T-076 de 1999, entre otras); derecho a la salud del enfermo de sida (T-177 de 1999); derecho a la seguridad social (SU-430 de 1998, entre otras); derecho a la subsistencia (T-140 de 1999); derecho a un ambiente sano (T-123 de 1999, entre otras); derecho al deporte (T-410 de 1999); derechos colectivos (T-244 de 1998, entre otras); derechos sociales, económicos y culturales (su-225 de 1998, entre otras).

Chinchilla ha desarrollado el argumento al indicar que, "sintetizando el pensamiento canonizado por la Corte Constitucional desde esos primeros pronunciamientos, se concluye que los derechos fundamentales se determinan por la mención expresa que de ellos haga la Constitución, por su significación misma para realización de los valores y principios consagrados en ella, por poseer ciertas posibilidades técnicas como la eficacia directa y el núcleo esencial, y, además, por la conexión que tenga en el caso concreto con otros derechos fundamentales expresamente consagrados como fundamentales o que lo sean por su conexión directa con la dignidad humana" (1999, p. 104). Incluso, la conexidad puede presentarse no solo como expresión directa de la dignidad humana, sino en relación con otros valores fundamentales. Sin embargo, esta posibilidad, abierta a través de la línea argumentativa de la Corte, no ha sido en los últimos tiempos muy utilizada. Por el contrario, se ha preferido la utilización del argumento de conexidad que resulta más sólido y menos azaroso, aunque el otro camino siga estando abierto y francamente inexplorado. Ahora bien, no cabe duda de que la manera en que se ha comprendido la conexidad se encuentra en una franca transformación, pese a que se le entendió desde la jurisprudencia alemana y española como forma excepcional de protección de un derecho no fundamental en relación con uno que sí lo es. Esto es así, porque en estos sistemas jurídicos los derechos cuentan con una lista cerrada, como se refirió. En el caso colombiano, la conexidad, con el paso del tiempo, ha demostrado, más bien, convertirse en el puente hacia expresiones más complejas del sistema de derechos como pueden ser las apuestas por la integralidad (Perdomo, 2011). Es decir, se señala aquí a aquellas posturas que plantean la interdependencia de todos los derechos, lo que implica que todos serían fundamentales. Si bien la Corte no ha llegado de forma directa a afirmar esto, sí ha reconocido derechos que formalmente o en la tradición liberal no son fundamentales, pero que dada la persistente conexidad y el desarrollo jurisprudencial se han reivindicado. El caso emblemático es, sin duda, el del derecho a la salud. Es posible, entonces, afirmar que quizás en un futuro no muy lejano se cuente con un sistema cada vez más volcado a esta manera compleja y holística de ver los derechos.

Por otra parte, resulta notorio el interés de los constituyentes por consagrar un gran número de derechos. Ello obedeció a dos causas: en primer lugar, a los conocedores del formalismo y de la versión exegético-positivista, que han tenido los jueces y diferentes operadores jurídicos-un positivismo reinterpretado-, una mención bastante reglamentaria de los derechos, que los garantizaría de mejor forma, ya que esperar a que la jurisprudencia y la doctrina los desarrollaran podría tornar ineficaz la realización del Estado social. Como ya se señaló, el constituyente quiso poner freno al positivismo-formalismo fuerte, que afectó en el pasado a los derechos, porque los convirtió en simples expresiones retóricas y desconoció su contenido material. Una mayor densidad de derechos hace que su inobservancia sea más difícil. En segundo lugar, si se establecen derechos de manera más explícita y detallada, los debates sobre ciertas doctrinas derivadas se evitan, ya que su existencia es patente y objetivada. Esto ocurre, por ejemplo, con el derecho al libre desarrollo de la personalidad, que en el estatuto anterior no figuraba y que hubiese podido derivarse como desarrollo del principio de autonomía y libertad personal, lo cual nunca 
ocurrió ni por vía de la interpretación jurisprudencial ni de la doctrina. La positivización de los derechos impulsa, con rapidez, los cambios que se propuso el constituyente. Por otra parte, consagrar una carta generosa en derechos es intentar consolidar la legitimidad a partir de la Constitución: más derechos más legitimidad. Esta idea puede parecer poco realista, pues la legitimidad se deriva más de la eficacia con la cual los derechos, muchos o pocos, sean disfrutados por sus destinatarios. Pero, a esta nota de realidad, se deben sumar dos circunstancias adicionales. De un lado, el proceso que condujo a la elaboración de la Carta, que resultó ser para todos los sectores participantes el receptáculo en el que querían plasmar antiguos reclamos en forma de derechos: consenso por derechos. De otro lado, la búsqueda de una nueva legitimidad, por lo menos desde un punto de vista formal y a la espera de que la conformación del órgano legislativo le confiriera realidad ${ }^{30}$.

\section{Los derechos en el sistema normativo: los derechos como sistema}

La Constitución de 1991 tiene como característica sobresaliente la consagración de los derechos. Esta preocupación sobre los derechos tiene que ver con los nexos que los estructuran: un obligado, una obligación y un acto materia de la obligación (Alexy, 1993). A partir de esta estructura se fundará el funcionamiento de buena parte del constitucionalismo de los años noventa y del presente siglo, que tendrá como una de sus tareas más importantes la incorporación de nuevos sujetos titulares de derecho y obligaciones con el propósito de "construir ciudadanía”. Esto implica la configuración y justificación de los individuos que de manera genérica aparecen dentro del Estado, a través de una vía pasiva. Dentro de este proceso de fijación de sujetos se especificarán las conductas que hacen acreedores a unos de acciones $\mathrm{u}$ omisiones frente a otros. Este sistema de relaciones, fundadas en

30 La Constitución no conforma el ser de la sociedad, pero sí tiene el deber de intentar corregir los defectos que existen en su interior. derechos, pone de manifiesto la importancia social que los derechos como lenguaje legitimador cumplen en el Estado social colombiano, al convertir las expresiones abiertas de los derechos en instrumentos útiles para alcanzar la paz social y la integración de diversos sectores excluidos. Este reto sigue vigente y seguramente debe acompañar el norte del posconflicto.

A pesar de la importante labor que cumplen los derechos como "lenguaje" constitucional (Ferreres Comella, 1997; Zagrebelsky, 2003), su adopción no asegura eliminar todas las contradicciones, ni evitar diversos tipos de dificultades. Son muchos los problemas que plantea el "lenguaje" de derechos como "lenguaje constitucional". Los más relevantes, en cuanto a enfrentar el reto integrador en la Constitución de 1991, son las barreras que se plantean para su aplicación como consecuencia de una sociedad escasamente politizada ${ }^{31}$; los posibles desequilibrios que un discurso como el de los derechos puede acarrear al principio de división de poderes $^{32}$, y las fisuras que, en particular, pueden ocasionarse al principio de legitimidad desde un punto de vista formal y material, por la irrupción de colisiones permanentes entre derechos (Cianciardo, 2000). Dados los objetivos de este escrito, no abordaremos los dos primeros elementos, pero es clave el desarrollo del último elemento como concepto central en la construcción y caracterización del sistema de derechos.

Todo sistema, y desde luego el sistema normativo, es descrito como una estructura que posee las características de completud y coherencia. La primera característica, desde la perspectiva constitucionalista, tiene que ver con el hecho de que la Constitución -o el derecho constitucional- conforma un subsistema completo, que se encuentra contenido en el sistema jurídico. Su completud radicará en la imposibilidad de que este carezca de

31 En dos sentidos, tanto como elemento desmovilizador como en el aspecto activo, pues aunque los derechos están consagrados la gente no los reclama (Waldron, 1996; Tushnet, 1984).

32 Sobre todo, ante el papel jurídico-político que adquiere la Corte Constitucional es posible revisar el capítulo de Schneider (1987). 
elementos definitorios o de que, en su desempeño, adolezca de las herramientas para su actuación. De la tesis de la plenitud del ordenamiento, pese a que pueda tener varios significados - teoría del espacio jurídico vacío (Bergbohm; Santi Romano), teoría de la norma general exclusiva (Kelsen y Zitermann), completud basada en la obligación de juzgar, completud fundada en la lógica deóntica, la tesis de Dworkin sobre la completud del ordenamiento basada en los tipos de reglas, entre otras-, lo que interesa en este punto es su concepto más elemental: el de la imposibilidad de que existan vacíos normativos o ausencia de normas. Esto resulta imposible en la Constitución de 1991, no por el carácter exhaustivo a la hora de establecer un sistema de derechos, sino por la vinculación material de todos los casos al principio de la legitimidad formal en los derechos, así como su relación con los valores y principios de la fórmula política. La dignidad humana, la democracia, la libertad, la igualdad y la justicia social son, sin lugar a duda, los principios de clausura del sistema constitucional. Es la constitución material la que permite esta afirmación. Con lo cual las aparentes lagunas, que se presentan desde una perspectiva formal, pueden ser llenadas con los contenidos de la materialidad preponderante. Esto trae como consecuencia que, ante una situación en la que se advierta una clara violación de algún valor de la Constitución, el operador jurídico, los jueces, podrá formalizar su defensa con fundamento en los pilares valorativos. Así las cosas, nuevos derechos pueden ser defendidos conforme las exigencias del respeto a la dignidad humana y de otros ejes axiológicos de la Constitución que así lo permitan ${ }^{33}$.

La otra nota relevante, a la hora de evaluar el sistema de derechos, es la que se refiere a su coherencia. Aquí es necesario hacer algunas precisiones. Todo sistema jurídico, además de las características citadas para todos los sistemas en general, está compuesto o integrado por normas jurídicas. Es decir, los sistemas jurídicos están

33 Este es el caso del mínimo vital, que carece de texto expreso, pero cuya defensa es evidente por su relación con la dignidad humana. Es posible ampliar este argumento en Díaz Revorio (1997). conformados por elementos que se denominan normas jurídicas y poseen la característica de la coercitividad y de la institucionalidad, vale decir, de un aparato que garantiza su cumplimiento. Para que se ejerza la coacción por incumplimiento de la norma, por parte de los órganos dispuestos para ello, se hace necesario que las normas gocen de validez. Muchas son las teorías sobre este tema -la de Kelsen, Austin, Hart y Raz-, pero todas ellas apuntan a la necesidad de la validez normativa como prerrequisito para la operatividad del sistema jurídico. Del tema de la validez nos interesará la diferenciación entre validez formal, que entiende que todas las normas pertenecen al sistema porque cumplen los requisitos formales para ser tales, o la validez material (Serrano, 1999), que enfatizará en los contenidos que requieren dichas normas para que puedan ser admitidas dentro del sistema jurídico. Es evidente que el sistema constitucional colombiano se inscribe en los dos tipos de validez, al considerar que las condiciones de la denominada validez formal son insuficientes para cumplir con los mandatos que la constitución exige desde el punto de vista material. Pero el problema se presenta cuando se enfrenta a un número tan extenso de derechos que se reputan necesariamente válidos, pues no puede considerarse a ningún derecho como descartable o inoperable, ya que todos hacen parte de la norma que funda el sistema. Con todo, al cotejar los distintos derechos, se evidencia un choque material entre ellos, al pertenecer unos y otros a tradiciones jurídicas y momentos históricos diversos. Ante estas situaciones, la técnica de coalición y la ponderación no es la salida única y definitiva, pues aquella se entiende como una herramienta del proceso que intenta disminuir las tensiones entre derechos (Cianciardo, 2000). Es en este punto en el que la interpretación material de la Constitución hace posible la coherencia del sistema, pues proporciona las herramientas que permiten soluciones más uniformes, que conducen a ordenar lo que el constituyente entregó como un "mundo normativo" complejo y muchas veces contradictorio. Así las cosas, por ejemplo, en el Estado social, el derecho de propiedad no corresponde al derecho de propiedad del siglo XIX; la libertad como derecho individual se transforma en virtud 
de la construcción de una visión de la persona consagrada en la constitución, distinta a la concepción individualista de ese mismo siglo. De este modo, los elementos que brinda la constitución, a partir de sus contenidos materiales, sirven para darle coherencia al subsistema normativo constitucional (Häberle, 2000).

A pesar de la función integradora que deben cumplir los valores y principios de la Carta, todos los conflictos no pueden solucionarse de manera satisfactoria, lo cual deja al legislador, y especialmente a la Corte Constitucional, en una posición privilegiada, ya que esta tiene que elaborar los discursos que faciliten la aplicación de las normas constitucionales. Así, tenemos dos posibles interpretaciones frente al orden de valores y sus conflictos. Por un lado, se puede concebir como la búsqueda de armonía de la Constitución, que es el ideal que subyace a toda aplicación de la Constitución. La pretensión según la cual todos los textos contenidos en ella se conforman como un rompecabezas perfecto. Esta idea de armonía es solo un tipo ideal, una idea regulativa del sistema. Por otro lado, la coherencia es el resultado que se obtiene una vez que el texto se expone a la luz de los hechos. Corresponde a la construcción continua de los valores y principios de la Carta, en un orden abierto y nunca definitivo. Es una constitución en conflicto permanente, pero este conflicto no la debilita, le hace más fuerte, pues es a través de aquel como logra su eficacia. La distinción es útil cuando se hace un estudio de las diferentes teorías con las que se puede hacer la interpretación de las normas constitucionales. En teorías como la de la integridad de Dworkin (1988), la coherencia está garantizada, pues todo el ordenamiento goza de unas normas inequívocamente superiores frente a otras, lo que hace que dicha teoría considere que la armonía no es un ente ideal, sino una realidad constitucional. Se presenta, por lo tanto, el orden constitucional como una estructura jerarquizada conformada por reglas y principios, que desempeñarán el otro requisito del sistema, su completud, ya que, en todo caso, siempre existirá una norma o principio que puede cubrir cualquier aparente vacío. Desde la materialidad de la Constitución de 1991, por el contrario, el sistema de valores, aunque encuentre salvaguardas para proteger su existencia, convive con el debate sobre el sistema y la jerarquía de sus valores, que permanece abierto, conforme se suman diversos elementos políticos y jurídicos; se trata de un debate que hace parte de la vida político-jurídica del Estado.

\section{Conclusiones}

Sin ser exhaustivo, se pueden considerar algunas conclusiones que servirán como pistas en investigaciones futuras. En primer lugar, el papel de los valores en la interpretación constitucional ha sido fundamental en el desarrollo de este nuevo constitucionalismo, pues desde su efecto de irradiación proporciona una dimensión que permite superar las dificultades del formalismo, radicadas principalmente en la inamovilidad del mismo sistema de derechos, así como en la ausencia de una conexión con la realidad de los sujetos de derechos, a quienes se dirige el texto constitucional. Ahora bien, estos valores también imponen retos serios en la argumentación, que deben superar, principalmente, la incapacidad de su predictibilidad en la aplicación, por un lado, y la paradoja de sobreprotección de los derechos (De Asis, 2000), por el otro, ya que, así como facilitan su desarrollo, también despiertan serias dudas en cuanto a la protección del principio de división de poderes y de seguridad jurídica; asuntos que son un reto permanente ante un sistema de garantías de derechos como el estudiado.

En segundo lugar, si bien el sistema dogmático de protección y definición de los derechos se ha desarrollado, en especial, el de los derechos fundamentales, también parece mostrar un agotamiento, dado que se requiere de un desarrollo armónico y sostenido con toda la Constitución. Aunque no se trató de forma amplia el asunto, no cabe duda de que el desarrollo orgánico de la constitución es una de las tareas pendientes para el robustecimiento de los derechos, pues los discursos de fundamentación y estructura de aquellos no garantizan su eficacia. Los pasos dados por el constitucionalismo de 1991 son enormes respecto a nuestra historia constitucional de los derechos, pero también debe advertirse que es apenas un punto en el camino, ya que claramente no cumple con la meta que la 
misma fórmula política plantea: la construcción de un país, fundado en la dignidad humana, sin desigualdades que vulneren a los individuos la posibilidad de construir su proyecto de vida.

\section{Referencias}

Aguilar de Luque, L. (2001). La noción de derechos fundamentales desde la perspectiva del constitucionalismo Iberoamericano. En Estudios de derecho constitucional. Valencia: Tirant Lo Blanch.

Alexy, R. (1993). Teoría de los derechos fundamentales. Madrid: Centro de Estudios Constitucionales.

Benda, E. (1996). La dignidad humana y derechos de la personalidad. En Manual de derecho constitucional. Madrid: Marcial Pons.

Borowski, M. (2003). La estrucutra de los derechos fundamentales. Bogotá: Universidad Externado de Colombia.

Botero Marino, C. (1991). La intervención del Estado en la economía colombiana, 1880-1936. Revista de Derecho Privado, 5(9), 6-103.

Bottomore, T. y Marshall, T. (1998). Ciudadanía y clase social. Madrid: Alianza.

Canosa Usera, R. (1988). Interpretación constitucional y fórmula política. Madrid: Centro de Estudios Constitucionales.

Chinchilla, T. E. (1999). Qué son y cuáles son los derechos fundamentales. Santra Fé de Bogotá: Temis.

Cianciardo, J. (2000). El conflictivismo en los derechos fundamentales. Pamplona: Eunsa.

Corte Constitucional. (1992). T-401.

Corte Constitucional. (1992). T-406.

Corte Constitucional. (1992). T-426.

Corte Constitucional. (1992). T-491.

Corte Constitucional. (1992). T-571.

Corte Constitucional. (1998). T-521.

Corte Constitucional. (1998). T-810.

Corte Constitucional. (1999). SU-062.

Corte Constitucional. (1999). C-155.

Cruz Villalon, P. (1989). Formación y evolución de los derechos fundamentales. Revista Española de Derecho Constitucional (25), 44.

De Asis Roig, R. (2004). Sobre el concepto y fundamento de los derechos. Madrid: Dykinson.

De Asis, R. (2000). Las paradojas de los derechos fundamentales como límites al poder. Madrid: Dykinson.
De Cabo Martín, C. (2001). El sujeto y sus derechos. Teoría $y$ realidad constitucional (7).

Díaz Revorio, F. J. (1997). Valores superiores e interpretaciónconstitucional. Madrid: Centro de Estudios Constitucionales.

Dworkin, R. (1988). El imperio de la justicia. Barcelona: Gedisa.

Estrada, A. (2000). La eficacia de los derechos fundamentales entre particulares. Bogotá: Universidad Externado de Colombia.

Ferrajoli, L. (2001). Los fundamentos de los derechos fundamentales. Madrid: Trotta.

Ferreres Comella, V. (1997). Justicia Constitucional y democracia. Madrid: Centro de Estudios Políticos y Constitucionales.

Häberle, P. (1997). La libertad fundamental en el Estado constitucional. Lima: Pontificia Universidad Católica del Perú.

Häberle, P. (2000). Teoría de la constitución como ciencia de la cultura. Madrid: Tecnos.

López Medina, D. (2000). El derecho de los jueces: obligatoriedad del precedente judicial. Bogotá: Legis.

Martínez Caballero, A. (1992). La constitución como norma objetiva. Revista de Derecho Público (2).

Molina, G. (1971). Las ideas liberales en Colombia, 18491914 (Vol. 1). Bogotá: Tercer Mundo.

Nino, C. S. (1989). Ética y derechos humanos. Barcelona: Ariel.

Nino, C. S. (1992). Fundamentos de derecho constiucional. Buenos Aires: Astrea.

Oehling de los Reyes, A. (2010). La dignidad de la persona. Madrid: Dykinson.

Pécaut, D. (1989). Crónica de dos décadas de política colombiana: 1968-1988. Bogotá: Siglo XXI.

Peces Barba, G. E. (1998). Los derechos económicos sociales y culturales: su génesis y su concepto. Derechos y Libertades: Revista del instituto Bartolomé de las Casas (6).

Peces Barba, G. E. (1999). Curso de derechos fundamentales. Teoría general. Madrid: Eudema Universidad.

Perdomo, C. A. (2011). Derechos fundamentales a medias e integralidad de los derechos. Bogotá: Defensoría del Pueblo.

Pérez Tremps, P. (2001). La interpretación de los derechos fundamentales. En López Guerra, Estudios de derecho constitucional, Homenaje al Prof. Joaquín García Morillo. Valencia: Tirant lo Blanch.

Restrepo Piedrahita, C. (1992). Las primeras constituciones de Colombia y Venezuela en el Primer Constitucionalismo Iberoamericano. Madrid: Marcial Pons. 
Schneider, J. P. (1987). Continencia judicial y estructura normativa abierta del derecho constitucional. En A. López Pina, División de poderes e interpretación (7376). Madrid: Tecnos.

Serna Bermudez, P. (1995). La dignidad humana como principio del Derecho público. Derechos y libertades (4).

Serrano, J. L. (1999). Validez y vigencia. Madrid: Trotta.

Tushnet, M. (1984). An Essay on Rights. Texas Law Review, 62(8).

Uribe Vargas, D. (1996). Evolución política y constitucional de Colombia. Madrid: Universidad Complutense.

Von Munch, I. (1982). La dignidad del hombre en el derecho constitucional. Revista Española de derechos constitucional (5).

Waldron, J. (1996). Rights and Needs: The Myth of Disjunction. En Legal Rights, Historical and Philosophical Perspectives. Universidad de Michigan.

Zagrebelsky, G. (2003). El derecho dúctil. Madrid: Trotta. 